Article

\title{
Promising Mechanical, Thermal, and Ballistic Properties of Novel Epoxy Composites Reinforced with Cyperus malaccensis Sedge Fiber
}

\author{
Lucas de Mendonça Neuba ${ }^{1}{ }^{\circledR}$, Raí Felipe Pereira Junio ${ }^{1}$, Matheus Pereira Ribeiro ${ }^{1}{ }^{\circledR}$, \\ Andressa Teixeira Souza ${ }^{1}{ }^{\circledR}$, Eduardo de Sousa Lima ${ }^{1}{ }^{(}{ }^{1}$, Fábio da Costa Garcia Filho ${ }^{2}$, \\ André Ben-Hur da Silva Figueiredo ${ }^{1}$, Fábio de Oliveira Braga ${ }^{3, *(D)}$, \\ Afonso Rangel Garcez de Azevedo ${ }^{4}$ (D) and Sergio Neves Monteiro ${ }^{1}$ \\ 1 Department of Materials Science, Military Institute of Engineering-IME, Rio de Janeiro 22290270, Brazil; \\ lucasmneuba@gmail.com (L.d.M.N.); raivsjfelipe@hotmail.com (R.F.P.J.); \\ m.pereiraribeiro@hotmail.com (M.P.R.); andressa.t.souza@gmail.com (A.T.S.); \\ sousalima@ime.eb.br (E.d.S.L.); abenhur@ime.eb.br (A.B.-H.d.S.F.); snevesmonteiro@gmail.com (S.N.M.) \\ 2 Department of Mechanical and Aerospace Engineering, University of California San Diego-UCSD, \\ La Jolla, CA 92093, USA; fdacostagarciafilho@eng.ucsd.edu \\ 3 Department of Civil Engineering, Federal Fluminense University-UFF, Niterói 24210240, Brazil \\ 4 Department of Agricultural and Environmental Engineering, Federal Fluminense University-UFF, \\ Niterói 24210240, Brazil; afonso.garcez91@gmail.com \\ * Correspondence: fabiobraga@id.uff.br
}

Received: 25 July 2020; Accepted: 6 August 2020; Published: 8 August 2020

\begin{abstract}
Composites reinforced with natural lignocellulosic fibers (NLFs) are gaining relevance as the worldwide demand for renewable and sustainable materials increases. To develop novel natural composites with satisfactory properties, less common NLFs should also be investigated. Among these, the Cyperus malaccensis (CM), a type of sedge fiber, is already used in simple items like ropes, furniture, and paper, but has not yet been investigated as composite reinforcement for possible engineering applications. Therefore, the present work evaluated for the first time the properties of novel epoxy composites incorporated with 10, 20, and 30 vol.\% of CM sedge fibers. Tensile, Izod-impact, and ballistic impact tests were performed, as well as Fourier transform infrared (FT-IR) spectroscopy and thermal analysis of the composites. Results disclosed a decrease (-55\%) in tensile strengths as compared to the neat epoxy. However, the elastic modulus of the 30 vol.\% sedge fiber composite increased (+127\%). The total strain and absorbed ballistic energy did not show significant variation. The Izod impact energy of the $30 \mathrm{vol}$ \% composite was found to be $181 \%$ higher than the values obtained for the neat epoxy as a control sample. An increase in both stiffness and toughness characterized a reinforcement effect of the sedge fiber. The thermal analysis revealed a slight decrease $(-15 \%)$ in the degradation temperature of the CM sedge fiber composites compared to the neat epoxy. The glass-transition temperatures were determined to be in the range of 67 to $81{ }^{\circ} \mathrm{C}$.
\end{abstract}

Keywords: natural fiber composite; Cyperus malaccensis; sedge; mechanical properties; thermal analysis; ballistic armor

\section{Introduction}

Synthetic fibers experienced exponential growth after the Second World War and became a successful class of engineering materials, mainly as reinforcement of polymer matrix composites. They have been applied in several technological fields of human interest, from surgical prostheses to aerospace components [1-3]. However, at the end of the last century, concerns on the widespread 
pollution caused by non-degradable materials, such as common plastics, as well as climate changes resulting from carbon dioxide emissions, motivated a tendency to replace synthetic by natural fibers in composite materials. These fibers, naturally produced by living organisms, such as animals [4] and plants [5], consume less energy to be processed and rapidly degrade in natural environments, reducing disposal problems and contributing to the sustainability of the projects.

Cellulose-rich natural lignocellulosic fibers (NLFs) have been gaining considerable interest as possible substitutes for the reinforcement phase of polymer composites [5-16], including totally biodegradable biocomposites [17]. Indeed, as compared to synthetic fibers, the NLFs display better characteristics, such as lower density and cost, as well as superior specific strength and elastic modulus $[18,19]$. Such characteristics are motivating applications in automotive, packaging, civil construction, and aerospace industries associated with NLF composites [20-26]. In particular, these composites are being considered for ballistic armors [27-30]. More recently, several researchers have been investigating the NLF waste as a source of nanocrystalline cellulose (NCC) [31-36], a strong nanomaterial, which can be used to produce several important products, such as nanocomposites, ion exchange membranes, films for electronics devices, and others [36].

Despite all the advantages, NLFs present some drawbacks associated with their polar incompatibility towards a non-polar nature of polymeric matrices. In this case, poor interfacial adhesion between the reinforcement and matrix phases is created, impairing the mechanical properties [6-14]. Another major limitation often encountered is thermal degradation. The decomposition reaction of the fiber components (cellulose, hemicellulose, and lignin) mainly occurs at low temperatures, around $200^{\circ} \mathrm{C}$, and imposes limitations to processing and application for the NLF-reinforced polymeric-matrix composites [37]. In the case of less known NLFs, it is important to study the thermal behavior of related polymer composites, in order to assure better processing and properties [38,39]. Among the less known NLFs, the several types of sedge only recently begun to be investigated [40-47] but have still not been cited in the aforementioned specialized reviews dedicated to technical properties of NLF polymer composites.

Babu et al. [40] evaluated polyester composites reinforced with Cyperus pangorei fibers treated with benzoyl chloride. They studied the tribological properties of the composites aiming the application as vehicle brakes. Babu et al. [41] investigated the mechanical and thermal properties of the Cyperus esculentus fiber-reinforced polypropylene composites, with and without mercerization. The mercerized specimens presented the best properties, as well as the $30 \mathrm{vol} \%$ fiber specimens. They obtained values as high as $\sim 70 \mathrm{MPa}$ of tensile strength, $\sim 60 \mathrm{MPa}$ of flexural strength, and $30 \mathrm{~J} / \mathrm{m}$ impact strength. Rajini et al. [42] studied the tribological properties of Cyperus pangorei fiber-reinforced polyester composites, such as hardness, friction coefficient, and surface roughness. Kalimuthu et al. [43] examined the mechanical properties and morphology of Cyperus pangorei fiber-reinforced polyester composites. They evaluated several fiber lengths and percentages of fibers. The best performance was observed for the $40 \mathrm{~mm}$ length fiber and 40 vol.\% fraction of fibers. The tensile strength was found as 57.7 MPa, and the flexural strength as 90.5 MPa. Vijay and Singaravelu [44] investigated the influence of the sandwiching stacking sequence of Cyperus pangorei fiber layers in the mechanical properties of laminated composites. They produced the specimens by stacking the C. pangorei layers within external glass fabric layers either with kenaf, sisal, or jute core layers. The best results were obtained by the kenaf-cored laminates, which presented $51.5 \mathrm{MPa}$ as tensile strength, $384.3 \mathrm{MPa}$ as flexural strength, and $8.17 \mathrm{~J}$ as impact strength. Mayandi et al. [45] performed a thorough characterization (mechanical, thermal, chemical, and structural) of the Cyperus Pangorei fibers. The values $196 \pm 56 \mathrm{MPa}$ and $11.6 \pm 2.6 \mathrm{GPa}$ were obtained as tensile strength and elastic modulus for the fibers, respectively. They also found out that the fibers were semicrystalline ( $\sim 41 \%$ crystallinity obtained by $X R D)$ and were stable until $221^{\circ} \mathrm{C}$. The general characteristics of these fibers, according to the authors, make them promising to composite reinforcement. Govindasamy et al. [46] evaluated the characteristics of the Cyperus malaccensis (CM) fibers for papermaking purposes. Benazir et al. [47] studied the chemical composition, structure, and some mechanical properties of mat sedge Cyperus pangorei yarns. 
They found out that the fibers were composed mainly of alpha-cellulose $(\sim 42 \%)$, hemicellulose $(\sim 42 \%)$, lignin $(\sim 13 \%)$, and waxes $(\sim 2 \%)$.

In particular, the $\mathrm{CM}$ sedge fiber has not yet been investigated for possible composite reinforcement but only for papermaking [46] or agricultural purpose [48]. Therefore, the objective of this work was for the first time to investigate the mechanical and thermal behavior of the $\mathrm{CM}$ sedge fiber-reinforced composites. Tensile, Izod-impact, and ballistic impact tests were performed, as well as Fourier transform infrared (FT-IR) and thermal analysis of the fibers and composites.

\section{Materials and Methods}

\subsection{Materials}

The CM sedge fibers were extracted from a plant known in China as "mat grass" and in Brazil as junco sete-ilhas (in a free translation "seven-islands sedge"). These CM sedges, found in the Brazilian southeast region of the Vale do Ribeira, are illustrated in Figure 1. A CM mat was acquired from the company Artevale, São Paulo, Brazil.
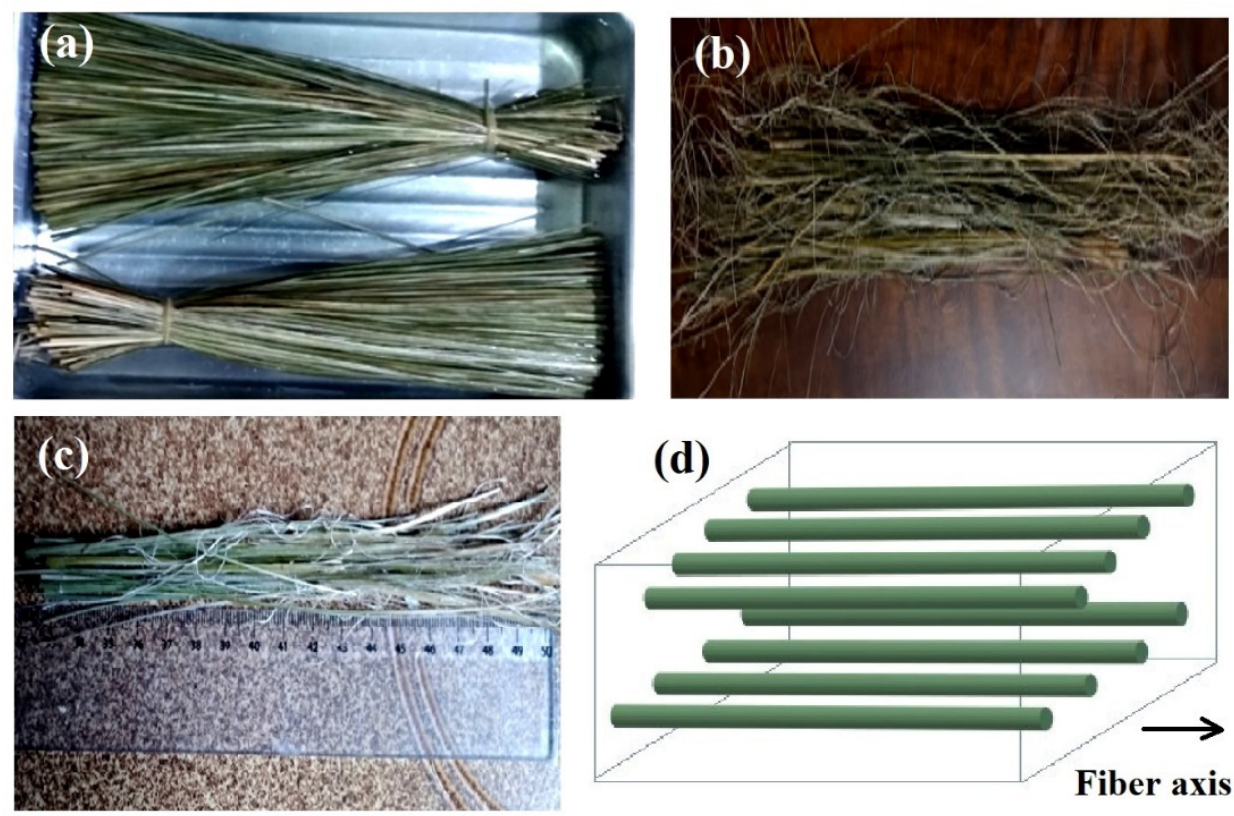

Figure 1. The extraction process of the fibers: (a) Cyperus malaccensis (CM) sedge immersed in water for a period of $24 \mathrm{~h}$; (b) shredded fibers; (c) fibers already cut $150 \mathrm{~mm}$ in length; (d) schematic diagram of the aligned arrangement of the fibers in the composite.

A commercial epoxy resin, diglycidyl ether of bisphenol A (DGEBA)-type, hardened with triethylene tetramine (TETA) in a $13 \mathrm{phr}$ stoichiometric ratio, was used as a polymeric matrix. It was fabricated by the company Dow Chemical, São Paulo, Brazil, and distributed by the company Resinpoxy Ltd.a, Rio de Janeiro, Brazil.

The extracted fibers were manually cleaned, immersed in water for $24 \mathrm{~h}$, Figure 1a, shredded, Figure $1 \mathrm{~b}$, cut to a $150 \mathrm{~mm}$ length, Figure $1 \mathrm{c}$, and then dried at $70^{\circ} \mathrm{C}$ for $24 \mathrm{~h}$. These fibers were not subjected to any chemical treatment. The immersion technique was adopted for providing greater flexibility and thus contributing to making the defibration process easier. Cutting tools helped in the process, assisting the removal of continuous fibers without sudden rupture, making it possible to obtain fibers with a larger length and quantity. 


\subsection{Composite Processing}

To produce the composite plates, a metal mold with rectangular dimensions of $150 \times 120 \times 12 \mathrm{~mm}$ was used. The aligned fibers were carefully accommodated inside the mold's cavity, schematically illustrated in Figure 1d, and the resin-hardener mix was poured into the mold in a previously calculated fiber/resin ratio. For these calculations, the fiber was measured by a geometric linear density method, which consists of precision-weighting about 100 fibers and measuring their diameter and length using an optical microscope. The calculated fiber density values were obtained by dividing the weight by the calculated volume, and then the mean value of $0.46 \mathrm{~g} / \mathrm{cm}^{3}$ was obtained. For the epoxy resin, the density value of $1.11 \mathrm{~g} / \mathrm{cm}^{3}$ was taken from the literature [49]. Specimens with 10, 20, and $30 \mathrm{vol} . \%$ fibers were produced. Finally, the mixture was kept under pressure of 5 tons for $24 \mathrm{~h}$ to assist the curing process. The final cure was performed at $60^{\circ} \mathrm{C}$ for one hour.

\subsection{FT-IR Analysis}

Fourier transform infrared (FT-IR) spectroscopy was performed in a model IR Prestige 21-FTIR Shimadzu equipment (Tokyo, Japan).

\subsection{Impact Tests}

For the Izod impact tests, 10 specimens for each group were cut from the composite plates, following the dimensions of the ASTM D256 standard [50] $(60.25 \times 12.7 \times 10 \mathrm{~mm})$. A $45 \pm 1^{\circ}$ and $2.54 \mathrm{~mm}$-deep V-notch was produced in each specimen, using a manual Pantec Iz/Ch-50 single-tooth carver. The impact tests were carried out in a model XC-50 Pantec machine, using a 22J hammer.

\subsection{Tensile Tests}

For the tensile tests, 6 specimens for each group were cut from the composite plates, following the dimensions of the ASTM D3039 standard [51]-150 $\times 15 \times 2 \mathrm{~mm}$ and gauge length of $90 \mathrm{~mm}$. The tests were conducted in an EMIC 23 equipment (Instron, São José dos Pinhais, Brazil), with a load capacity of $20 \mathrm{kN}$ and a crosshead speed of $2 \mathrm{~mm} / \mathrm{min}$.

\subsection{Ballistic Tests}

Composite plates were prepared for the ballistic tests, one for each condition, with the dimensions of $15 \times 12 \times 19 \mathrm{~cm}^{3}$, comprising of 5 test-shots for each plate. A Gunpower SSS pressure air rifle (Ashford, UK) (4000 psi) was used to perform the test-shots, with $22 \mathrm{~mm}$ commercial ammunition (estimated mass of $3.3 \mathrm{~g}$ ). A model MK3 Air Chrony gun chronograph (Nové Město, Czech Republic), with a precision of $0.15 \mathrm{~m} / \mathrm{s}$, was used for the impact velocity measurements. A model Pal ProChrono gun chronograph (Competition Eletronics, Rockford, IL, USA), with a precision of $0.31 \mathrm{~m} / \mathrm{s}$, was used for the residual velocity measurements. The former was positioned $10 \mathrm{~cm}$ before the target to measure the impact velocity, and the latter was placed $10 \mathrm{~cm}$ after the target to measure the residual velocity. The specimens were firmly positioned $5 \mathrm{~m}$ away from the rifle, and the bullet trajectory was perpendicular to the target plate.

As mentioned before, the projectile's velocity was measured immediately before $\left(V_{i}\right)$ and after $\left(V_{r}\right)$ the impact. The kinetic energy variation was related to the energy absorbed by the target $\left(\mathrm{E}_{\mathrm{abs}}\right)$ and used for comparison between the tested materials [52].

$$
E_{a b s}=\frac{m\left(V_{i}^{2}-V_{R}^{2}\right)}{2}
$$

where: $m=$ mass of the projectile. 
Another calculation was performed for the limit velocity $\left(V_{L}\right)$, which is estimative of the velocity that the target would be able to stop the projectile, once $V_{r}$ is considered zero.

$$
V_{L}=\sqrt{\frac{2 E_{a b s}}{m}}
$$

The results of the mechanical and ballistic tests were statistically treated by analysis of variance (ANOVA) to verify if there were significant differences between the averages, with a $95 \%$ confidence level. The mean values were then compared using Tukey's test, also called honestly significant difference (HSD), calculated as follows.

$$
\mathrm{HSD}=\mathrm{q} \sqrt{\frac{E M S}{r}}
$$

where: $q=$ HSD constant tabulated for $5 \%$ significance; EMS = error mean square of the ANOVA; $r=$ number of repetitions for each treatment [53].

\subsection{Thermal Analysis}

Thermal analyses of the composites were performed by two methods: thermogravimetry (TGA) and differential scanning calorimetry (DSC). The materials were comminuted and placed in a platinum crucible. A model DTG-60H Shimadzu equipment (Tokyo, Japan) was used, with a heating rate of $10^{\circ} \mathrm{C} / \mathrm{min}$, starting at 30 up to $600^{\circ} \mathrm{C}$, on a nitrogen atmosphere, with a gas flow of $50 \mathrm{~mL} / \mathrm{min}$.

\subsection{Materials}

Microscopic analyses of the fibers were performed by scanning electron microscopy (SEM) in a model Quanta FEG 250 Fei microscope (Thermofisher scientific, Hillsboro, OR, USA), operating with secondary electrons between 5 and $15 \mathrm{kV}$.

\section{Results and Discussion}

The Fourier transform infrared (FT-IR) spectrum of the CM sedge fiber is shown in Figure 2. In this spectrum, an absorption band appears at $3430 \mathrm{~cm}^{-1}$, which is attributed to the axial vibration of hydroxyl groups $(\mathrm{O}-\mathrm{H})$ of the cellulose [54]. The band found at $2923 \mathrm{~cm}^{-1}$ refers to the vibration of $\mathrm{CH}_{2}$ and $\mathrm{CH}_{3}$ molecules of the organic structure of NLFs. The relatively small amplitude of this band in the CM sedge fiber might justify a low interaction with the polymer matrix during the eventual manufacture of composites [54]. The band at $2361 \mathrm{~cm}^{-1}$ is assigned to the bond between organic molecules. The band at $1648 \mathrm{~cm}^{-1}$ is related to $\mathrm{C}=\mathrm{O}$ aromatic groups, and the band at $1254 \mathrm{~cm}^{-1}$ to the $\mathrm{C}-\mathrm{O}$ and $\mathrm{C}-\mathrm{C}$ bonds. The bands at 1030 and $446 \mathrm{~cm}^{-1}$ are attributed to $\mathrm{C}-\mathrm{O}$ and $\mathrm{C}-\mathrm{C}$ deformation of the respective covalent bonds.

Table 1 presents the results for all Izod impact tests for the different composite materials. They showed a low energy absorption capacity when compared to other different composites reinforced with natural lignocellulosic fibers (NLFs) $[55,56]$. The tested specimens were completely fractured, as expected, which is required for the validity of the tests, as shown in the macrographs in Figure 3. 


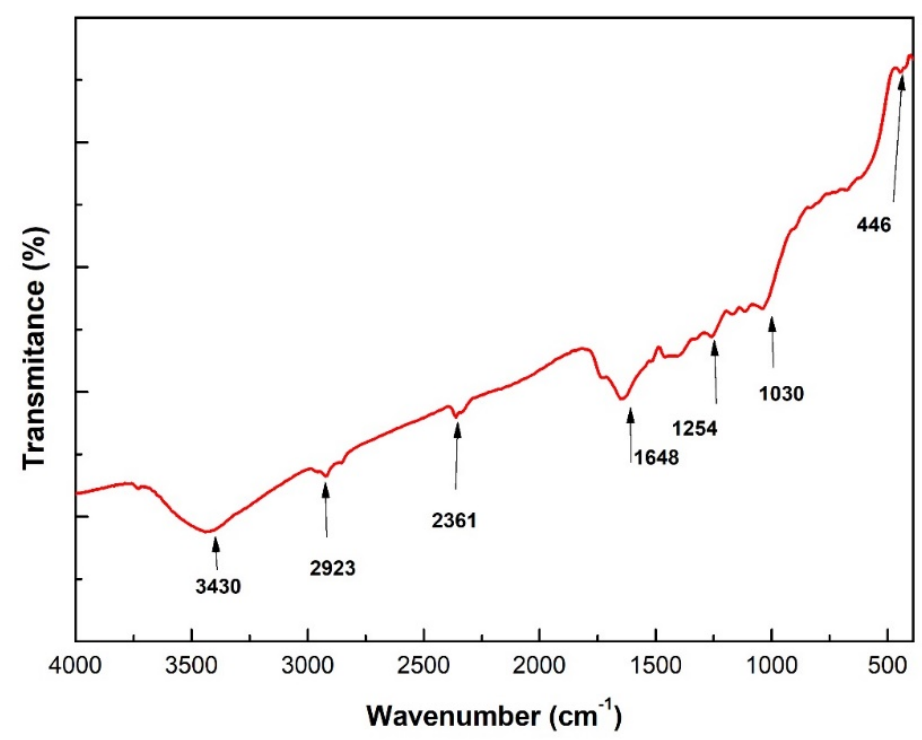

Figure 2. Fourier transform infrared (FT-IR) spectrum of the CM sedge fiber.

Table 1. Izod impact energies for the neat epoxy resin and Cyperus malaccensis (CM) fiber-reinforced composites.

\begin{tabular}{ccccc}
\hline \multicolumn{5}{c}{ Izod Impact Energy (J/m) } \\
\hline Specimen & Neat Epoxy Resin & 10 vol.\% Fibers & 20 vol.\% Fibers & 30 vol.\% Fibers \\
\hline $\mathbf{1}$ & 19.5 & 9.7 & 48.5 & 68.4 \\
$\mathbf{2}$ & 14.5 & 33.5 & 66.3 & 80.6 \\
$\mathbf{3}$ & 19.5 & 17.5 & 43.5 & 58.8 \\
$\mathbf{4}$ & 14.7 & 11.5 & 59.1 & 78.7 \\
$\mathbf{5}$ & 14.7 & 20.4 & 40.5 & 67.6 \\
$\mathbf{6}$ & 24.6 & 46.5 & 33.5 & 59.2 \\
$\mathbf{7}$ & 19.6 & 39.2 & 42.6 & 38.7 \\
$\mathbf{8}$ & 19.6 & 17.5 & 24.4 & 79.0 \\
$\mathbf{9}$ & 38.9 & 22.4 & 45.1 & 59.3 \\
$\mathbf{1 0}$ & 43.8 & 22.9 & 65.6 & 39.6 \\
\hline Average & $\mathbf{2 2 . 4} \mathbf{9 . 2}$ & $\mathbf{2 3 . 3} \mathbf{\mathbf { 1 0 . 5 }}$ & $\mathbf{4 3 . 7} \pm \mathbf{1 2 . 3}$ & $\mathbf{6 3 . 0} \mathbf{\mathbf { 1 4 } . 3}$ \\
\hline
\end{tabular}
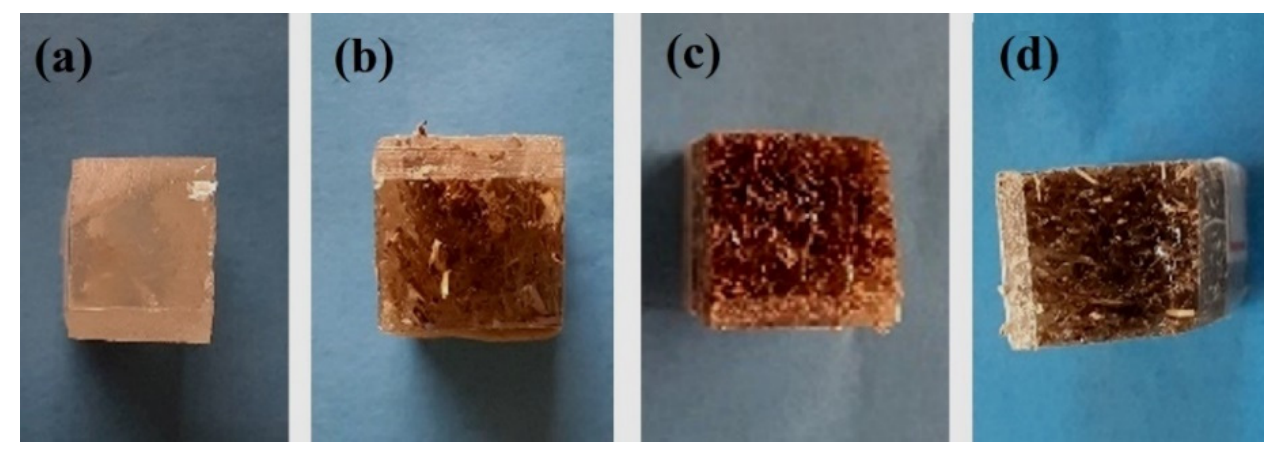

Figure 3. Fractured specimens after Izod impact test: (a) neat epoxy resin; (b) 10 vol.\% of CM fibers; (c) 20 vol.\% of CM fibers; (d) 30 vol.\% of CM fibers.

The results in Table 1 can be better visualized by the graph in Figure 4. A tendency of increasing impact energy with increasing fiber fraction was observed, as already observed for other NFL polymer composites $[55,56]$. The effect of incorporating 30 vol.\% fibers as reinforcement in composites was remarkable, producing a $181 \%$ increase when compared to the value obtained for the neat epoxy resin. 


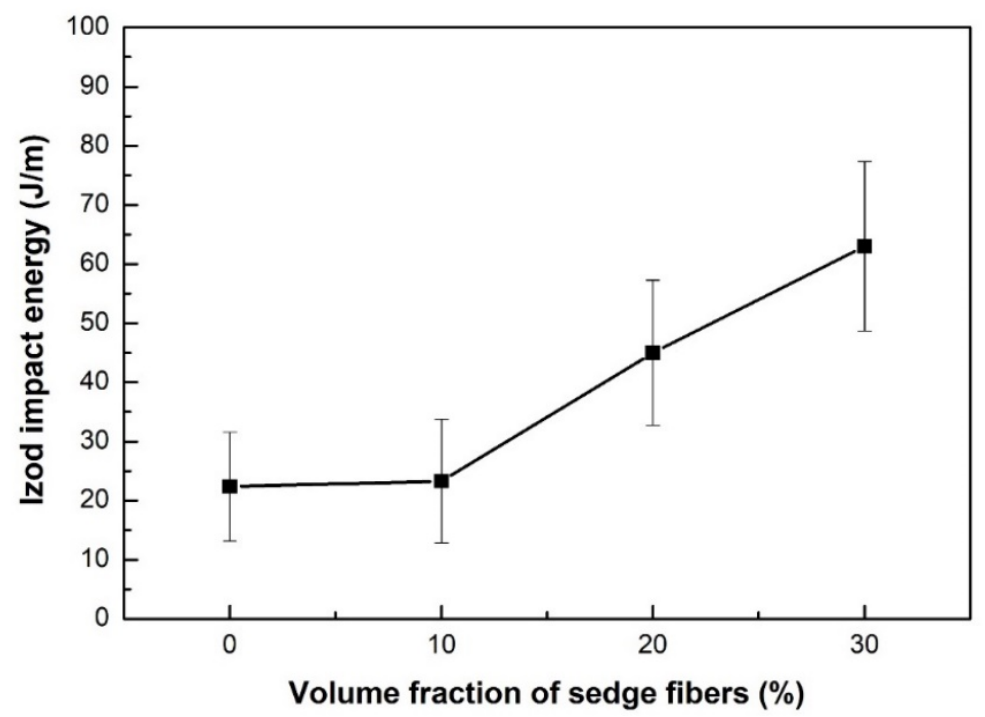

Figure 4. Izod impact energy as a function of the fiber fraction for the neat epoxy resin and CM fiber-reinforced composites.

ANOVA was conducted to confirm if there is a significant difference between the Izod impact energy average results. According to Table 2, the hypothesis that the averages are equal was rejected, with a level of significance of $5 \%$, since the calculated $\mathrm{F}$ (statistical parameter of ANOVA) was higher than the critical $\mathrm{F}_{\mathrm{c}}$ (tabulated). Therefore, it was confirmed that there was indeed a significant difference between the impact energy for the different materials.

Table 2. Analysis of variance for the Izod impact energy of the neat epoxy resin and CM sedge fiber-reinforced composites.

\begin{tabular}{cccccc}
\hline Causes of Variation & Degrees of Freedom & Sum of Squares & Mean Square & $\mathbf{F}$ (Calculated) & $\mathbf{F}_{\mathbf{c}}$ (Tabulated) \\
\hline Treatments & 3 & 11188.5 & 3729.5 & 22.68 & 2.87 \\
Residue & 36 & 5918.6 & 164.4 & & \\
Total & 39 & 17107.2 & & & \\
\hline
\end{tabular}

Table 3 shows the results of the Tukey's honestly significant difference (HSD) test. The calculated HSD was $16.32 \mathrm{~J} / \mathrm{m}$, and thus the differences above the HSD were considered significant. These values are marked in bold in Table 3 and showed that the impact strength of the 30 vol.\% sedge fiber composites was better than all other tested specimens.

Table 3. HSD (honestly significant difference) test for the Izod impact energy of the neat epoxy resin and CM sedge fiber-reinforced composites.

\begin{tabular}{ccccc}
\hline Volume Fraction of Sedge Fibers & $\mathbf{0} \%$ & $\mathbf{1 0} \%$ & $\mathbf{2 0} \%$ & $\mathbf{3 0} \%$ \\
\hline $0 \%$ & 0 & 1.20 & $\mathbf{2 3 . 9 9}$ & $\mathbf{4 0 . 0 9}$ \\
$10 \%$ & 1.2 & 0 & $\mathbf{2 2 . 7 9}$ & $\mathbf{3 8 . 8 9}$ \\
$20 \%$ & $\mathbf{2 3 . 9 9}$ & $\mathbf{2 2 . 7 9}$ & 0 & $\mathbf{1 6 . 1}$ \\
$30 \%$ & $\mathbf{4 0 . 0 9}$ & $\mathbf{3 8 . 8 9}$ & $\mathbf{1 6 . 1 0}$ & 0 \\
\hline
\end{tabular}

The impact test results were now compared to the results for the other fibers of the Cyperus family, investigated as possible reinforcement to polymers, as presented in Table 4 [41,43]. The composites of the present work displayed better impact strength when compared to the other composites with related sedge fibers. 
Table 4. Impact resistance comparison of composites reinforced with different natural fibers belonging to the Cyperus family.

\begin{tabular}{ccccc}
\hline Matrix & Fiber Species & Volume Fraction $\mathbf{( \% )}$ & Impact Resistance $\mathbf{( J / m )}$ & Reference \\
\hline \multirow{2}{*}{ Epoxy } & & 10 & 23.3 & $\mathrm{PW}^{1}$ \\
& Cyperus malaccensis & 20 & 45 & \\
\hline \multirow{3}{*}{ Polypropylene } & 30 & 63 & {$[41]$} \\
& \multirow{3}{*}{ Cyperus esculentus } & 10 & 10 & \\
& & 20 & 18 & {$[43]$} \\
\hline
\end{tabular}

${ }^{1}$ PW-Present work.

SEM observations of the surface aspects of the fibers are shown in Figure 5. A relatively rough fiber surface can be noticed (Figure 5a), which is generally considered a good feature for composite materials, since it might improve the adhesion between fiber and matrix by mechanical interlocking in the fiber-matrix interface. However, higher magnification images showed inhomogeneities, such as the rougher regions contrasting to the smoother regions in Figure $5 \mathrm{~b}$. Microcracks can be observed (arrows) in the inset of Figure $5 b$, which might be attributed to degradation by the SEM electron beam power.
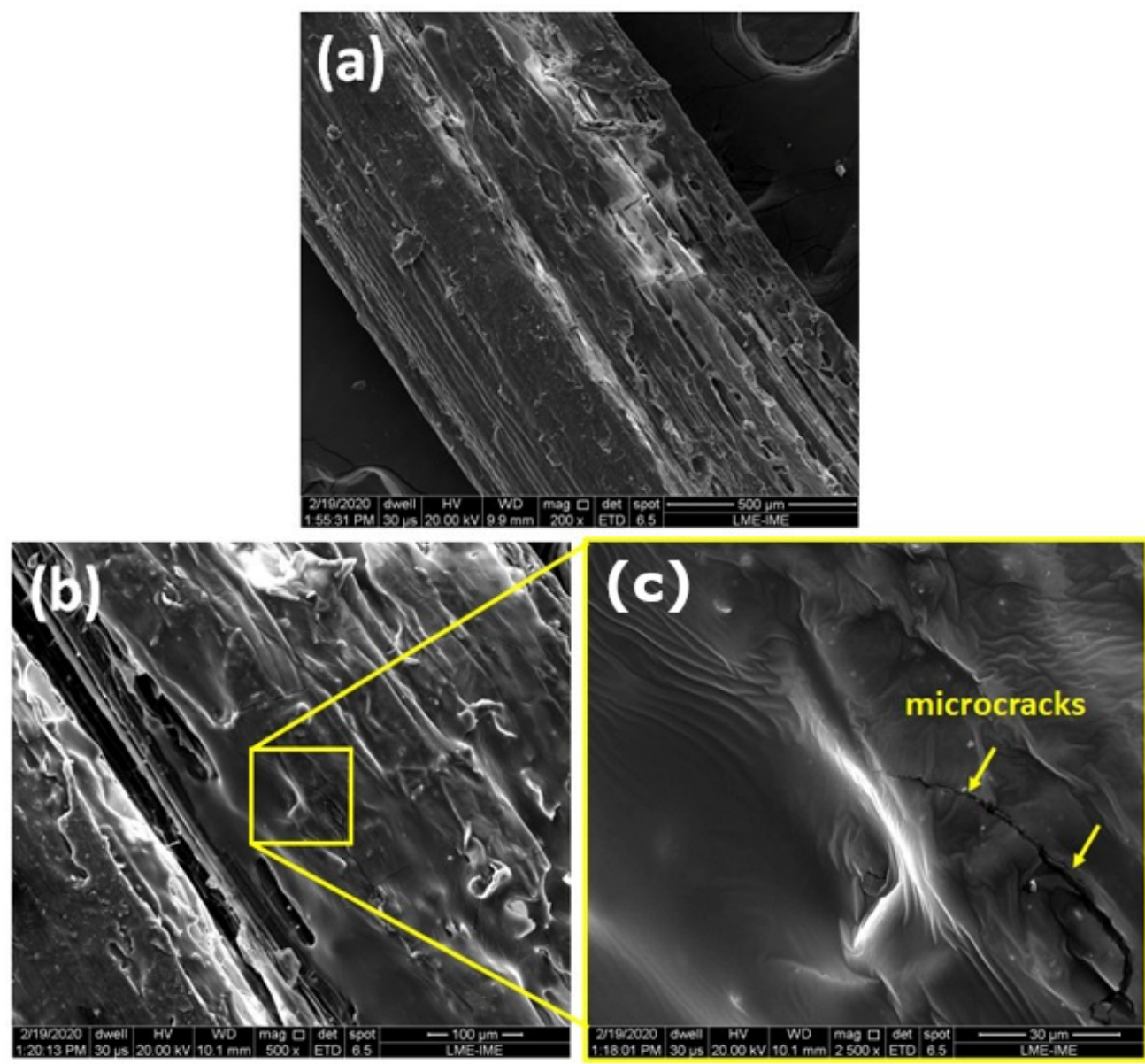

Figure 5. SEM images of the CM sedge fibers with magnifications of (a) 200×; (b) 500x; (c) 2500×.

Table 5 shows the average results for the tensile strength of the CM sedge fiber-reinforced composites. Table 5 also shows literature values for the tensile strength of the same neat epoxy 
resin [57]. The results displayed comparatively poor tensile properties for the CM sedge-reinforced composites. In fact, the values of tensile strength for all composites were lower than that for the neat epoxy resin. This indicated that the fibers did not act as reinforcement when tensile loads were applied to the material. In this case, the fibers probably acted as defects in the material's structure, and the tensile properties of the fiber-matrix interface were impaired. This was consistent with the small $2923 \mathrm{~cm}^{-1}$ band found in the FT-IR spectrum in Figure 2 for the CM sedge fiber.

Table 5. Tensile strength results for the CM fiber-reinforced composites.

\begin{tabular}{ccc}
\hline Volume Fraction (\%) & Tensile Strength (MPa) & Reference \\
\hline 0 & $34.3 \pm 4.2$ & \\
10 & $7.0 \pm 3.1$ & \\
20 & $12.4 \pm 5.5$ & \\
30 & $15.2 \pm 3.6$ & $\mathrm{PW}^{1}$ \\
\hline
\end{tabular}

The results in Table 5 can be better visualized by the graph in Figure 6. Although there is a tendency of increasing tensile strength with the fiber fraction, as already mentioned, the values were significantly lower when compared to the neat epoxy resin. An apparent contradiction is a fact that the sedge fibers improve the impact properties of the material. However, as observed before [56], the low interface strength resulted in a greater fracture surface. Consequently, it might provide better impact properties to the material, even though the tensile strength was lower.

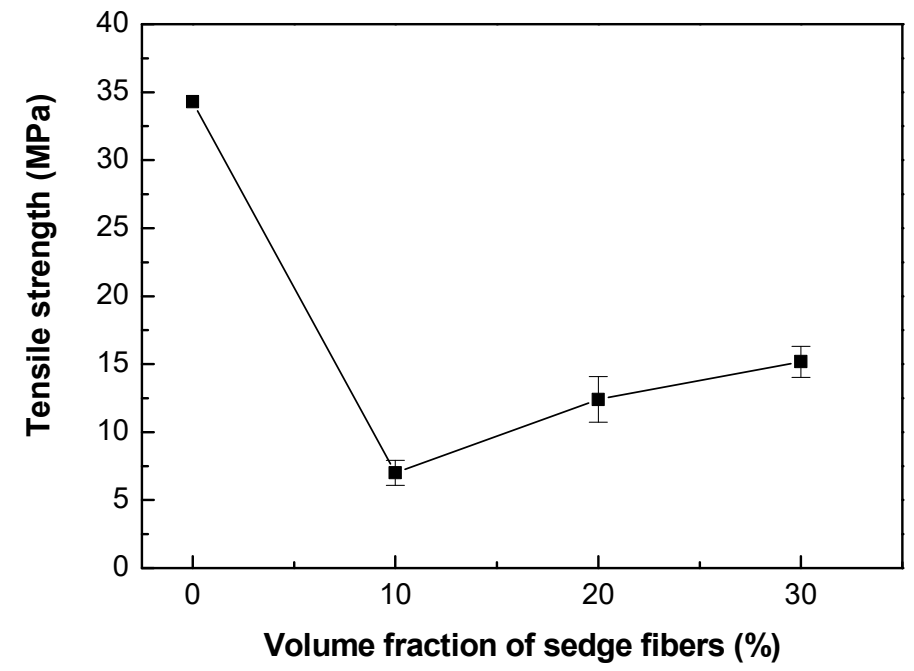

Figure 6. Tensile strength as a function of the fiber fraction for the neat epoxy resin and CM sedge fiber-reinforced composites.

Table 6 shows the ANOVA for the tensile strength of the composites. According to Table 6, the hypothesis that the averages are equal was rejected, with a level of significance of $5 \%$, since the calculated $\mathrm{F}$ was higher than the critical $\mathrm{F}_{\mathrm{c}}$ (tabulated). Therefore, it was confirmed that there was a significant difference between the tensile strength for the different $\mathrm{CM}$ sedge fiber composites.

Table 6. Analysis of variance for the tensile strength of the CM sedge fiber-reinforced composites.

\begin{tabular}{cccccc}
\hline Causes of Variation & Degrees of Freedom & Sum of Squares & Mean Square & $\mathbf{F}$ (Calculated) & $\mathbf{F}_{\mathbf{c}}$ (Tabulated) \\
\hline Treatments & 2 & 379.2 & 189.6 & 9.38 & 3.32 \\
Residue & 30 & 606.7 & 20.2 & & \\
Total & 32 & 985.8 & & & \\
\hline
\end{tabular}


Table 7 shows the results of the Tukey's honestly significant difference (HSD) test for the tensile strength. The calculated HSD was $5.46 \mathrm{MPa}$, and thus the differences above the HSD were considered significant. These values are marked in bold in Table 7 and showed that the tensile strength of the 30 vol.\% CM sedge fiber composites was better than all other tested specimens.

Table 7. HSD test for the tensile strength of the CM sedge fiber-reinforced composites.

\begin{tabular}{cccc}
\hline Volume Fraction of Sedge Fibers & $\mathbf{1 0} \%$ & $\mathbf{2 0} \%$ & $\mathbf{3 0} \%$ \\
\hline $10 \%$ & 0 & 5.4 & $\mathbf{8 . 1 6}$ \\
$20 \%$ & 5.4 & 0 & 2.76 \\
$30 \%$ & $\mathbf{8 . 1 6}$ & 2.76 & 0 \\
\hline
\end{tabular}

Furthermore, through the data obtained by the tensile test, it was possible to calculate the elastic modulus of the composites and their total strain. The results are presented in Table 8 and Figures 7 and 8.

Table 8. Total strain and elastic modulus results for the CM sedge fiber-reinforced composites.

\begin{tabular}{cccc}
\hline Volume Fraction (\%) & Total Strain (\%) & Elastic Modulus (GPa) & Reference \\
\hline 0 & $3.0 \pm 1.0$ & $1.66 \pm 0.46$ & {$[45]$} \\
10 & $4.0 \pm 1.2$ & $0.56 \pm 0.19$ & $\mathrm{PW}^{1}$ \\
20 & $4.3 \pm 0.6$ & $1.32 \pm 0.40$ & \\
30 & $4.7 \pm 1.1$ & $3.77 \pm 0.05$ & \\
\hline
\end{tabular}

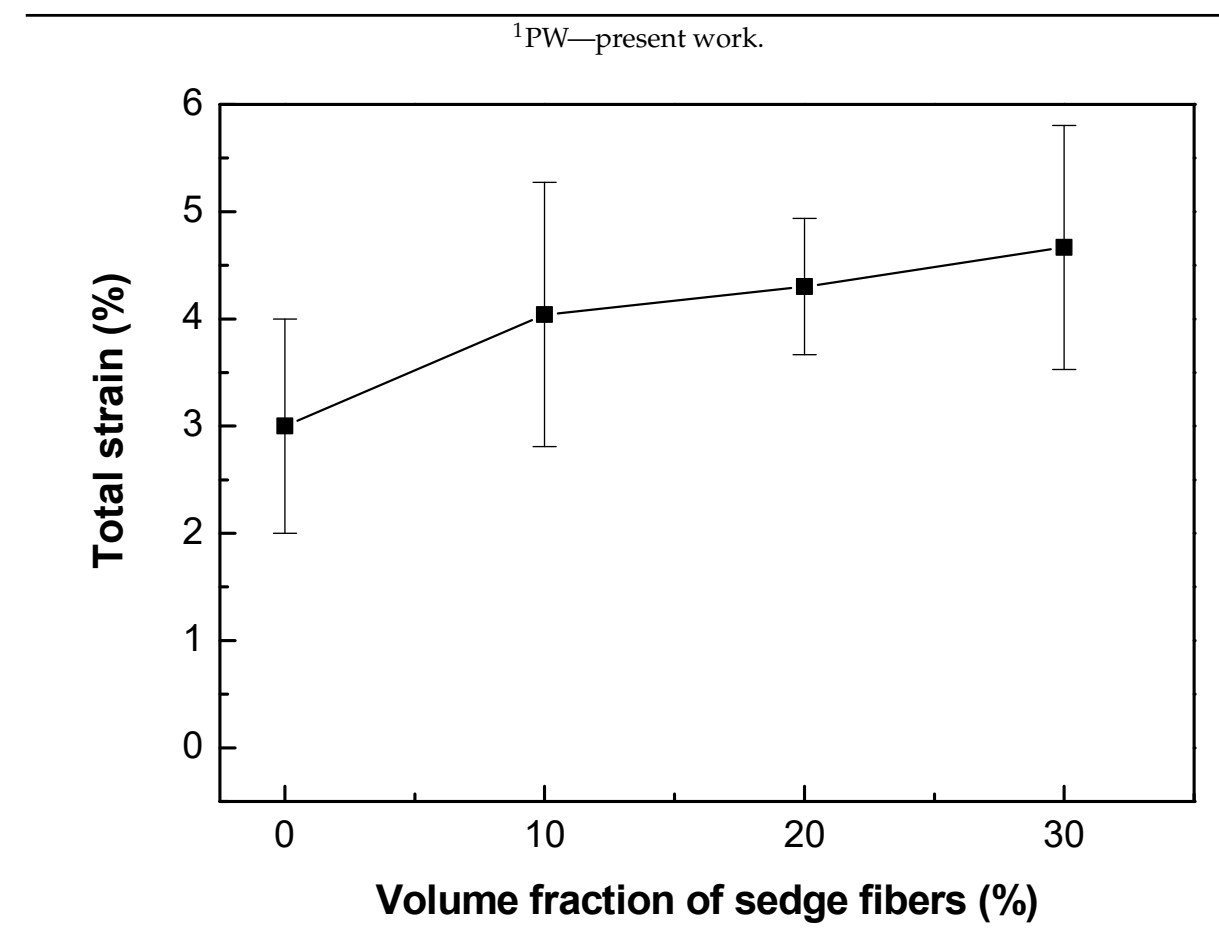

Figure 7. Total strain as a function of the fiber fraction for the neat epoxy resin and CM sedge fiber-reinforced composites.

According to Table 8 and Figure 8, it is possible to observe a clear tendency of increasing the elastic modulus of the composites as the volumetric fraction of fibers increases, probably because of the higher stiffness of the fibers. Comparing to literature data for the same epoxy resin [58], only the 30 vol.\% CM fiber-reinforced composite showed higher modulus, probably due to difficulties in load transfer in the fiber-matrix interface. On the other hand, the total strain graph, Figure 7, did not show any significant variation between the different materials, within the standard deviation. 


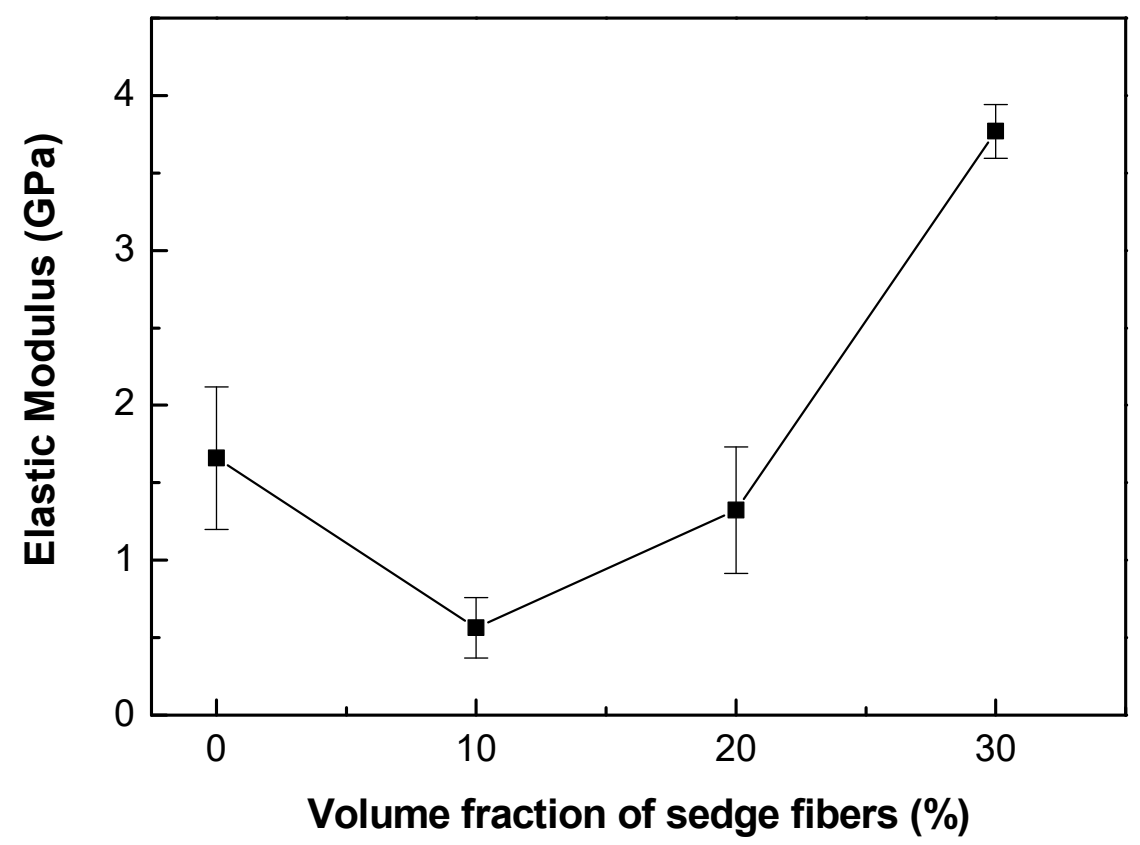

Figure 8. Elastic modulus as a function of the fiber fraction for the neat epoxy resin and CM sedge fiber-reinforced composites.

Preliminary tensile results for the CM sedge fiber indicated a maximum strength of $164 \mathrm{MPa}$, an elastic modulus of $4.4 \mathrm{GPa}$, and a total strain of $4.1 \%$. In particular, the CM sedge fiber maximum strength was significantly higher than the epoxy matrix, $34.3 \mathrm{MPa}$, in Table 5. However, the aforementioned low fiber/epoxy interfacial strength was responsible for the inferior strength of the composites in Figure 6, in spite of the higher impact energy, Figure 4, and elastic modulus, Figure 8, reinforcement effect. CM sedge fiber treatment, especially as has been done for other NFLs with graphene oxide [59], is expected to substantially improve the composites' tensile strength.

The tensile test results were also compared to the results for the other fibers of the Cyperus family (Table 9), investigated by [41,43]. It is important to mention that these authors performed the tests according to the ASTM D638 standard [60]; besides, the polymeric matrices are also different, so the results might not be directly comparable to the present results. However, comparing the properties, it is worth to have some idea of the property values for similar materials. According to Table 9, the Cyperus malaccensis composites presented similar mechanical properties when compared to those of Cyperus esculentus and C. pangorei composites.

Table 9. Tensile strength and elastic modulus comparison of composites reinforced with different natural fibers belonging to the Cyperus family.

\begin{tabular}{|c|c|c|c|c|c|}
\hline Matrix & Fiber Species & Volume Fraction (\%) & $\begin{array}{c}\text { Tensile Strength } \\
\text { (MPa) }\end{array}$ & $\begin{array}{l}\text { Tensile Modulus } \\
\text { (GPa) }\end{array}$ & Reference \\
\hline \multirow{3}{*}{ Epoxy } & \multirow{3}{*}{$\begin{array}{l}\text { Cyperus } \\
\text { malaccenis }\end{array}$} & 10 & 7 & 0.6 & \multirow{3}{*}{$\mathrm{PW}^{1}$} \\
\hline & & 20 & 12 & 1.3 & \\
\hline & & 30 & 15 & 3.8 & \\
\hline \multirow{3}{*}{ Polypropylene } & \multirow{3}{*}{$\begin{array}{l}\text { Cyperus } \\
\text { esculentus }\end{array}$} & 10 & 35 & 1.2 & \multirow{3}{*}[41]{} \\
\hline & & 20 & 40 & 1.6 & \\
\hline & & 30 & 50 & 1.9 & \\
\hline \multirow{3}{*}{ Polyester } & \multirow{3}{*}{$\begin{array}{l}\text { Cyperus } \\
\text { pangorei }\end{array}$} & 10 & $20-25$ & $2-2.3$ & \multirow{3}{*}[45]{} \\
\hline & & 20 & $20-30$ & $2.3-2.6$ & \\
\hline & & 30 & $30-40$ & $2.6-2.7$ & \\
\hline
\end{tabular}

${ }^{1} \mathrm{PW}$-present work. 
Table 10 shows the results of the ballistic tests. Values of absorbed energy during the impact of the projectile with the materials $\left(\mathrm{E}_{\mathrm{abs}}\right)$ and the calculated limit velocity $\left(\mathrm{V}_{\mathrm{L}}\right)$ are presented. All the specimens were perforated during the tests, so their residual velocities could be successfully measured. It is expected that the higher the absorbed energy, the better is the ballistic performance. From the data obtained, it was not shown any significant variation between the different materials.

Table 10. Absorbed energy in the ballistic test and limit velocity for the epoxy resin and for the CM sedge fiber-reinforced composites.

\begin{tabular}{cccc}
\hline \multicolumn{4}{c}{ Absorbed Energy (J) } \\
\hline Performed Shootings & 10 vol.\% Fibers & 20 vol.\% Fibers & 30 vol.\% Fibers \\
\hline $\mathbf{1}$ & 82.5 & 83.2 & 74.9 \\
$\mathbf{2}$ & 81.7 & 94.7 & 93.0 \\
$\mathbf{3}$ & 86.0 & 71.0 & 72.7 \\
$\mathbf{4}$ & 77.9 & 62.0 & 60.2 \\
$\mathbf{5}$ & 74.5 & 70.8 & 69.0 \\
\hline Average value & $\mathbf{8 0 . 5} \pm \mathbf{1 . 5}$ & $\mathbf{7 6 . 3} \pm \mathbf{2 . 5}$ & $\mathbf{7 4 . 0} \pm \mathbf{2 . 5}$ \\
\hline \multicolumn{5}{c}{ Average value } & $\mathbf{2 2 1 . 5} \pm \mathbf{5 . 5}$ & $\mathbf{2 1 5 . 2} \pm \mathbf{1 5 . 9}$ \\
\hline
\end{tabular}

Table 11 presents the ANOVA for the absorbed energy in the ballistic test. According to Table 11, since $\mathrm{F}$ calculated was smaller than $\mathrm{F}_{\mathrm{c}}$ (tabulated), the hypothesis that the averages are equal was accepted (with a level of significance of $5 \%$ ). Therefore, it was confirmed that there was no significant difference between the absorbed energy of the different materials.

Table 11. Analysis of variance for the absorbed energy in the ballistic test of the CM sedge fiber-reinforced composites.

\begin{tabular}{cccccc}
\hline Causes of Variation & Degrees of Freedom & Sum of Squares & Mean Square & $\mathbf{F}$ (Calculated) & $\mathbf{F}_{\mathbf{c}}$ (Tabulated) \\
\hline Treatments & 2 & 109.0 & 54.5 & 0.50 & 2.81 \\
Residue & 12 & 1306.4 & 108.9 & & \\
Total & 14 & 1415.5 & & & \\
\hline
\end{tabular}

Figures 9 and 10 show the thermogravimetric (TG) and its derivative (DTG) curves, respectively, for the neat epoxy resin and the composites reinforced with 10, 20, and 30 vol.\% of CM sedge fibers. The curves for the different materials presented similar features. Observing the TG curves in Figure 9, there was a small mass loss $(<5 \%)$ at low temperatures (until $200^{\circ} \mathrm{C}$ ), which was attributed to moisture desorption. For the neat epoxy resin, for example, the mass loss was extremely low, $1.64 \%$, due to its hydrophobic nature (little water absorption). For the composites, the mass loss in this stage was slightly higher, ranging from 3 to $4.2 \%$, due to the higher moisture absorption capacity of the sedge fibers that are now present in the structure.

At higher temperatures, degradation and rupture of the polymeric chains occurred, with severe mass loss. This occurred at $\mathrm{T}_{\text {onset }}=345^{\circ} \mathrm{C}$ for the neat epoxy resin, with a maximum rate at $389{ }^{\circ} \mathrm{C}$ (Figure 10), resulting in a 70.59\% mass loss in Figure 9. A third stage occurring at temperatures ranging from 455 to $600{ }^{\circ} \mathrm{C}$ resulted in a final formation of ash corresponding to about $19.6 \%$ of the initial mass, also shown in Figure 9. For the composites, the degradation occurred at lower temperatures, as previously reported $[39,61]$, at $\mathrm{T}_{\text {onset }}=292^{\circ} \mathrm{C}$ for the $10 \mathrm{vol} . \%$ fiber-composites, $\mathrm{T}_{\text {onset }}=287^{\circ} \mathrm{C}$ for the 20 vol. $\%$ fiber-composites, and $\mathrm{T}_{\text {onset }}=301^{\circ} \mathrm{C}$ for the $30 \mathrm{vol} . \% \mathrm{CM}$ fiber-composites. These temperatures could be considered as a first limit for the thermal stability of the $\mathrm{CM}$ sedge fiber-reinforced composites. Another difference between the epoxy resin and the composites was related to the temperature corresponding to the maximum rate of degradation, shown in the DTG curves in Figure 10, where 
the composites had a temperature ranging from 334 to $362{ }^{\circ} \mathrm{C}$, which was slightly lower than $389^{\circ} \mathrm{C}$ registered for the neat epoxy resin.

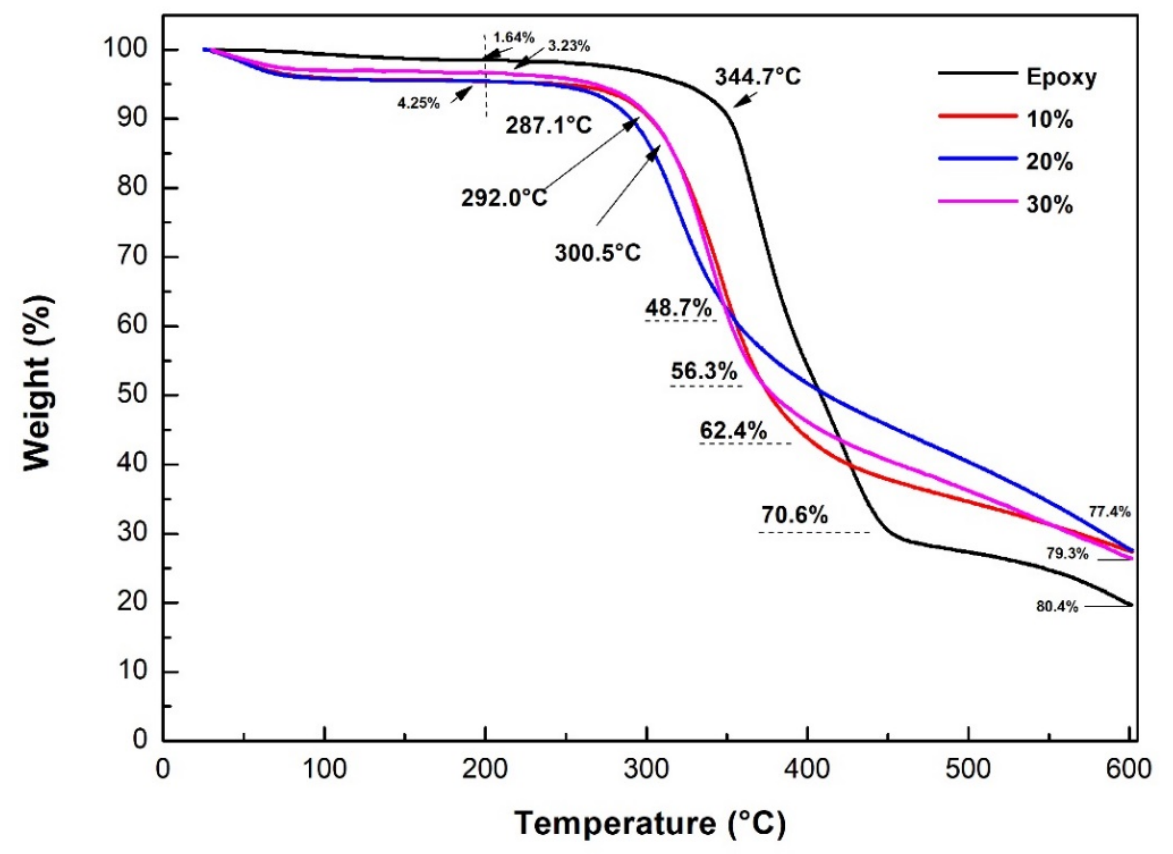

Figure 9. TG curves for the epoxy resin and for the CM sedge fiber-reinforced composites.

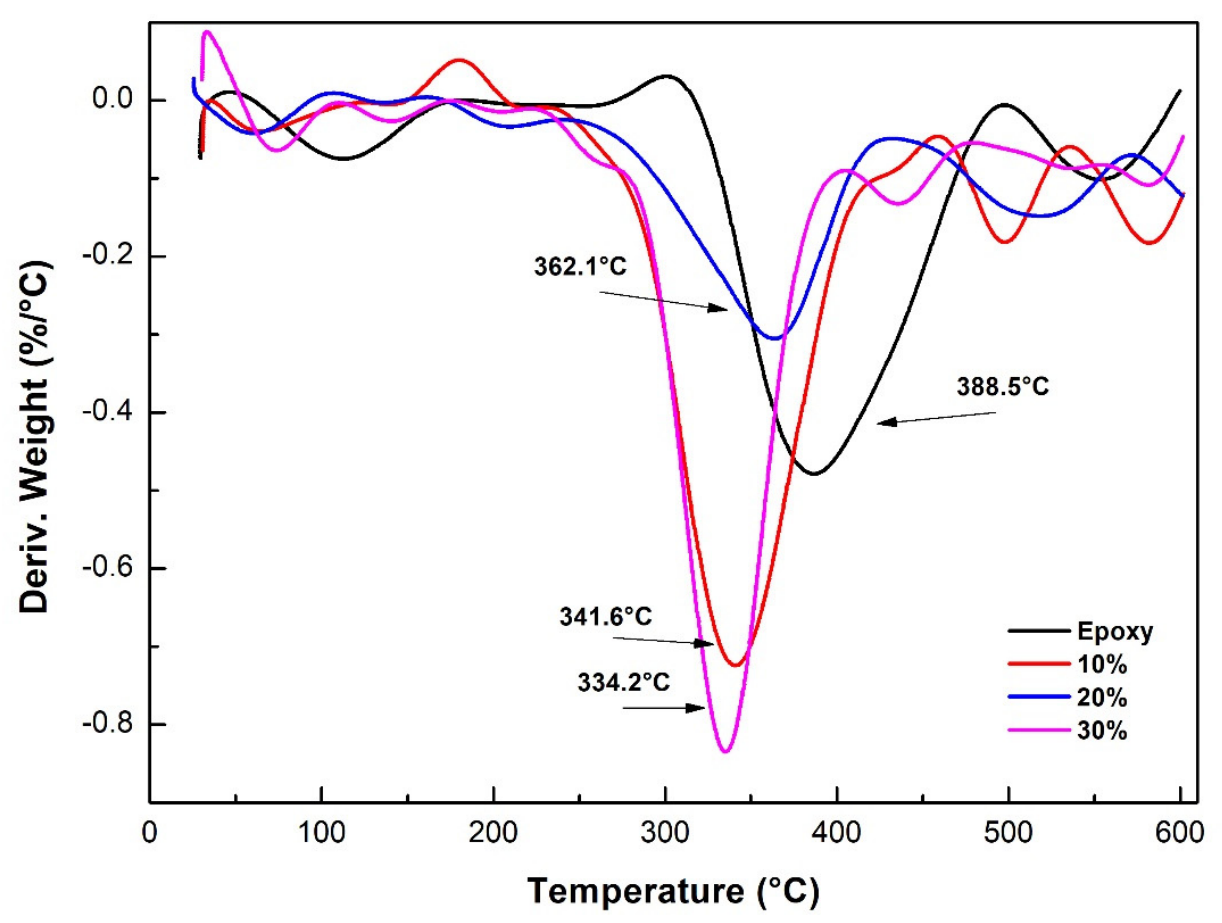

Figure 10. DTG curves for the epoxy resin and for the sedge fiber-reinforced composites.

Table 12 presents the main thermogravimetric parameters, temperatures, and mass loss for the neat epoxy, $0 \%$ fiber, and $\mathrm{CM}$ sedge fiber-reinforced composites. 
Table 12. Thermogravimetric parameters for the neat epoxy and the CM sedge fiber-reinforced composite.

\begin{tabular}{cccccc}
\hline $\begin{array}{c}\text { Volume Fraction } \\
\text { of Sedge Fiber (\%) }\end{array}$ & $\begin{array}{c}\text { Mass Loss } \\
\text { up to } \\
\mathbf{2 0 0}{ }^{\circ} \mathbf{C}(\mathbf{\%})\end{array}$ & $\begin{array}{c}\text { Initial } \\
\text { Degradation } \\
\text { Temperature }\left({ }^{\circ} \mathbf{C}\right)\end{array}$ & $\begin{array}{c}\text { Temperature of } \\
\text { Maximum } \\
\text { Degradation Rate }\left({ }^{\circ} \mathbf{C}\right)\end{array}$ & $\begin{array}{c}\text { Mass Loss at the } \\
\text { End of Second } \\
\text { Stage (\%) }\end{array}$ & $\begin{array}{c}\text { Mass Loss at } \\
\mathbf{6 0 0}{ }^{\circ} \mathbf{C}(\mathbf{\%})\end{array}$ \\
\hline 0 & 1.64 & 344.7 & 388.5 & 70.6 & 80.4 \\
10 & 4.23 & 300.5 & 341.6 & 62.4 & 79.3 \\
20 & 4.18 & 287.1 & 362.1 & 48.7 & 77.6 \\
30 & 3.23 & 292.0 & 334.2 & 56.3 & 77.4 \\
\hline
\end{tabular}

Lignin is the first structural component of NLFs to begin its degradation process at lower temperatures from $220{ }^{\circ} \mathrm{C}$ and continues above $440{ }^{\circ} \mathrm{C}$ [39]. Thus, the degradation of lignin is directly responsible for the thermal stability limit of a composite reinforced with NLFs.

Figure 11 shows the DSC curves for the neat epoxy resin and for the sedge fibers-reinforced composites. The curve for the epoxy resin showed an endothermic peak at $81.1^{\circ} \mathrm{C}$, which was associated with the glass transition temperature $(\mathrm{Tg})$. Regarding the curves representing the composites, endothermic peaks ranging between 66.8 and $81.1{ }^{\circ} \mathrm{C}$ could be observed, also associated with the $\mathrm{Tg}$. Changes in the baseline on temperatures ranging from 119 to $122.9^{\circ} \mathrm{C}$ might be related to a post-curing process, as evidenced in the isolated DSC curve for the $30 \mathrm{vol} \% \mathrm{CM}$ sedge fiber composite in Figure $12[62,63]$. The decrease in $\mathrm{Tg}$ for the composites, as compared to the neat epoxy, was due to the interference of $\mathrm{CM}$ sedge fiber with the $3 \mathrm{D}$ organization of the polymer macromolecules. This is a common event for NLF composites [39], which does not compromise the thermal stability for the usual engineering application since stiffness and hardness are not significantly changed.

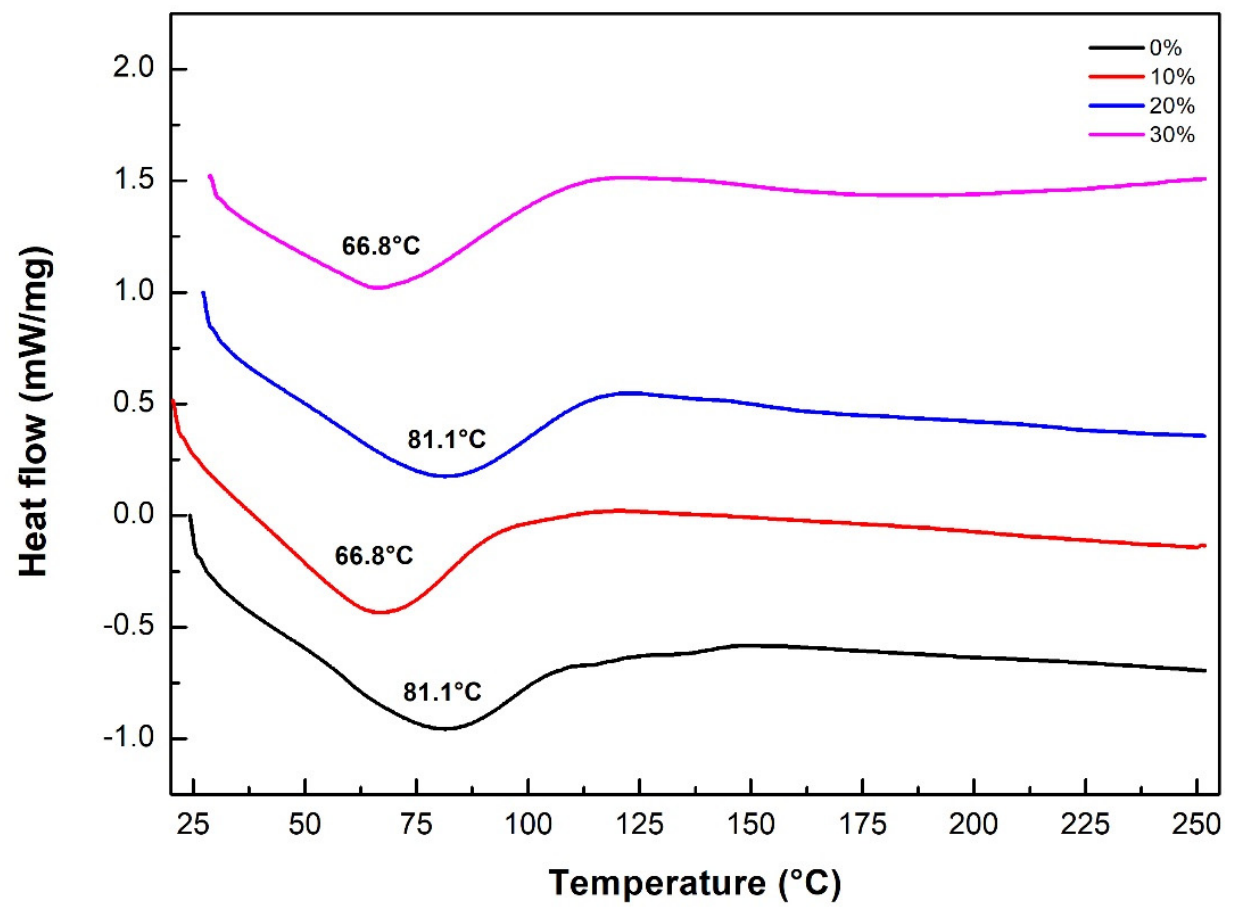

Figure 11. DSC curves for the neat epoxy resin and for the CM sedge fibers reinforced composites. 


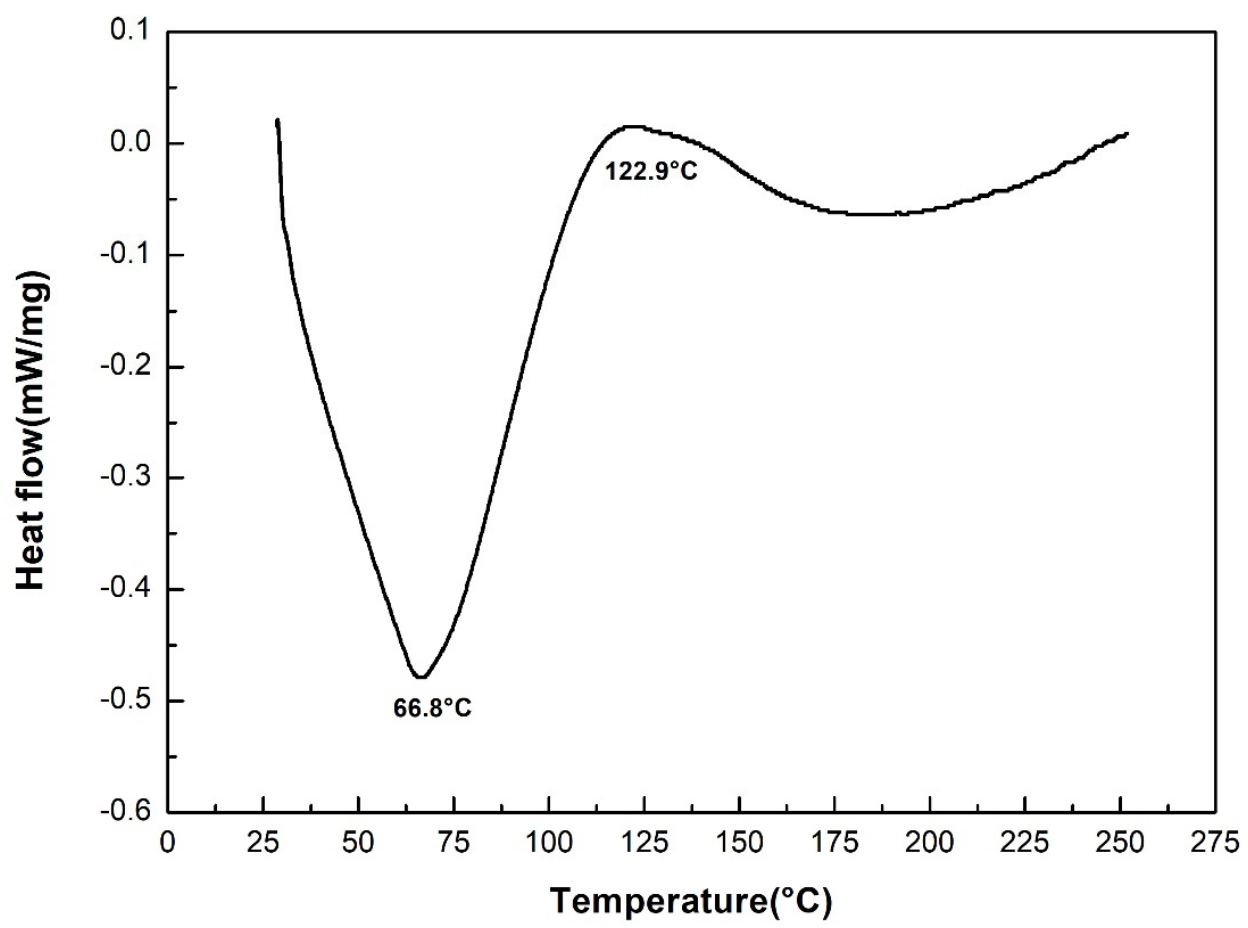

Figure 12. Isolated DSC curve for the 30 vol.\% sedge fiber-reinforced composites.

\section{Summary and Conclusions}

In the present work, mechanical, ballistic, and thermal behavior of the Cyperus malaccensis (CM) sedge fiber-reinforced composites were, for the first time, investigated. The main conclusions are:

- There was a tendency of increasing impact strength of the CM sedge fiber-reinforced composites with increasing fiber fraction. The best result was obtained by incorporating 30 vol.\% CM fibers as reinforcement, producing a $181 \%$ increase in the Izod impact energy when compared to the values obtained for the neat epoxy resin.

- The CM sedge fiber-reinforced composites presented relatively low tensile strength, showing values below that for the neat epoxy resin. This indicated that the fibers probably acted more as defects in the structure of the weak fiber-matrix interface.

- There was also a tendency of increasing elastic modulus of the composites as the CM fiber fraction increases, which was attributed to the higher stiffness of the fibers. However, a comparison to literature values for the neat epoxy resin showed that only the $30 \mathrm{vol} . \% \mathrm{CM}$ sedge fiber-reinforced composite showed higher modulus than the resin. This was attributed to difficulties in load transfer through the weak fiber-matrix interface.

- The total strain and the absorbed energy during ballistic tests did not show any significant variation between the different $\mathrm{CM}$ sedge fiber composites.

- The thermal behavior of the neat epoxy resin and the CM sedge fiber composites were similar, showing slight differences in the temperatures in which the thermal processes occurred. First, there was little mass loss at low temperatures up to $200{ }^{\circ} \mathrm{C}$, attributed to moisture desorption. This phenomenon was less significant to the neat epoxy resin (only $1.64 \%$ of mass loss) than for the composites ( 3 to $4.2 \%$ of mass loss around $100{ }^{\circ} \mathrm{C}$ ). At higher temperatures, degradation and rupture of the polymeric chains occurred for all materials, with severe mass loss. This process was activated at around $345^{\circ} \mathrm{C}$ for the neat epoxy resin and at lower temperatures ranging from 287 to $300^{\circ} \mathrm{C}$ for the $\mathrm{CM}$ sedge fiber composites. 
- The glass transition event was identified by the DSC method. Glass transition temperatures ( $\mathrm{Tg})$ were obtained as $81.1^{\circ} \mathrm{C}$ for the neat epoxy resin and ranging from 66.8 to $81.1^{\circ} \mathrm{C}$ for the $\mathrm{CM}$ sedge fiber composites.

- Both mechanical reinforcement and relative thermal stability up to $200{ }^{\circ} \mathrm{C}$ disclosed a potential application of CM sedge fiber epoxy composites as substitutes for fiberglass common use.

Author Contributions: L.d.M.N. prepared testing specimens, analyzed the data, and wrote the paper; R.F.P.J., M.P.R., and A.T.S. prepared testing specimens; E.d.S.L., F.d.C.G.F., A.B.-H.d.S.F., and A.R.G.d.A. performed the tests. S.N.M. conceived and coordinated the project and reviewed the paper. F.d.O.B. wrote and reviewed the paper. All authors have read and agreed to the published version of the manuscript.

Funding: This research received no external funding.

Acknowledgments: The authors wish to thank the support to this investigation by the Brazilian agencies: $\mathrm{CNPq}$, CAPES, FAPERJ, the Navy Research Institute (IPQM) for the thermal analyses conduction, the laboratory of applied mechanics at EEIMVR/UFF for conducting the composites tensile tests, and the Natural Fibers Laboratory at the State University of the North Fluminense Darcy Ribeiro (UENF) for conducting the impact tests.

Conflicts of Interest: The authors declare no conflict of interest.

\section{References}

1. Agarwal, B.D.; Broutman, L.J. Analysis and Performance of Fiber Composites, 2nd ed.; John Wiley \& Sons: Hoboken, NJ, USA, 1990.

2. Ashbee, K.H. Fundamental Principles of Fiber Reinforced Composites, 2nd ed.; CRC Press: Lancaster, PA, USA, 1993.

3. Chawla, K.K. Composite Materials Science and Engineering; Springer Science \& Business: New York, NY, USA, 2012.

4. Hamidi, Y.K.; Yalcinkaya, M.A.; Guloglu, G.E.; Pishvar, M.; Amirkhosravi, M.; Altan, M.C. Silk as a Natural Reinforcement: Processing and Properties of Silk/Epoxy Composite Laminates. Materials 2018, 11, 2135. [CrossRef]

5. Zhang, Z.; Cai, S.; Li, Y.; Wang, Z.; Long, Y.; Yu, T.; Shen, Y. High Performance of Plant Fiber Reinforced Composites-A New Insight from Hierarchical Microstructures. Compos. Sci. Technol. 2020, 194, 108151. [CrossRef]

6. Sanjay, M.R.; Madhu, P.; Jawaid, M.; Senthamaraikannan, P.; Senthil, S.; Predeep, S. Characterization and Properties of Natural Fiber Polymer Composites: A comprehensive review. J. Clean. Prod. 2018, 172, 566-581. [CrossRef]

7. Pickering, K.L.; Efendy, M.G.A.; Le, T.M. A Review of Recent Developments in Natural Fibre Composites and their Mechanical Performance. Compos. Part A 2016, 83, 98-112. [CrossRef]

8. Güven, O.; Monteiro, S.N.; Moura, E.A.B.; Drelich, J.W. Re-Emerging Field of Lignocellulosic Fiber-Polymer Composites and Ionizing Radiation Technology in their Formulation. Polym. Rev. 2016, 56, 702-736. [CrossRef]

9. Mohammed, L.; Ansari, M.N.M.; Pua, G.; Jawaid, M.; Islam, M.S. A Review in Natura Fiber Reinforced Polymer Composites and its applications. Int. J. Polym. Sci. 2015, 2015, 243947. [CrossRef]

10. Faruk, O.; Bledzki, A.K.; Fink, H.-P.; Sain, M. Progress Report on Natural Fiber Reinforced Composites. Macromol. Mater. Eng. 2014, 299, 9-26. [CrossRef]

11. Thakur, V.K.; Thakur, M.K.; Gupta, R.K. Review: Natural Fibers Based Polymer Composites. Int. J. Anal. Charact. 2014, 19, 256-271. [CrossRef]

12. Shah, D.U. Developing Plant Fiber Composites for Structural Applications by Optimizing Composites Parameters: A critical Review. J. Mater. Sci. 2013, 48, 6083-6107. [CrossRef]

13. Faruk, O.; Bledzki, A.K.; Fink, H.-P.; Sain, M. Biocomposites Reinforced with Natural Fibers: 2000-2010. Prog. Polym. Sci. 2012, 37, 1552-1596. [CrossRef]

14. Monteiro, S.N.; Lopes, F.P.D.; Ferreira, A.S.; Nascimento, D.C.O. Natural Fiber Polymer Matrix Composites: Cheaper, Tougher and Environmentally Friendly. JOM 2009, 61, 17-22. [CrossRef]

15. Radzuan, N.A.M.; Tholibon, D.; Sulong, A.B.; Muhamad, N.; Haron, C.H. Effects of High-Temperature on the Mechanical Properties of Kenaf Composites. Polymers 2020, 12, 1643. [CrossRef] [PubMed]

16. Wang, H.; Hassan, E.A.M.; Memonm, H.; Elagib, T.H.H.; Alladris, F.A. Characterization of Natural Composites Fabricated from Abutilon-Fiber-Reinforced Poly (Lactic Acid). Processes 2019, 7, 583. [CrossRef] 
17. Wang, H.; Memon, H.; Hassan, E.A.M.; Elagib, T.H.H.; Hassan, F.E.A.A.; Yu, M. Rheological and Dynamic Mechanical Properties of Abutilon Natural Straw and Polylactic Acid Biocomposites. Int. J. Polym. Sci. 2019, 2019, 8732520. [CrossRef]

18. Monteiro, S.N.; Lopes, F.P.D.; Barbosa, A.P.; Bevitori, A.B.; Silva, I.L.A.; Costa, L.L. Natural lignocellulosic fibers as engineering materials-An overview. Metall. Mater. Trans. A 2011, 42, 2963-2974. [CrossRef]

19. Satyanarayana, K.G.; Arizaga, G.C.; Wypych, F. Biodegradable Composites Based on Lignocellulosic Fibers-An Overview. Prog. Polym. Sci. 2009, 34, 982-1021. [CrossRef]

20. Potluri, R.; Krishna, N.C. Potential and applications of green composites in industrial space. Mater. Today Proc. 2020, 22, 2041-2048. [CrossRef]

21. Youssef, A.M.; El-Sayed, S.M. Bionanocomposite materials for food packaging applications: Concepts and future outlook. Carbohydr. Polym. 2018, 193, 19-27. [CrossRef]

22. Di Bella, G.; Fiore, V.; Galtieri, G.; Borsellino, C.; Valenza, A. Effect of Natural Fibres Resinforcement in Lime Plasters (Kenaf and Sisal vs. Polypropilene). Constr. Build. Mater. 2014, 58, 159-165. [CrossRef]

23. Majeed, K.; Jawaid, M.; Hassan, A.; Bakar, A.A.; Khalil, H.P.S.A.; Salema, A.A.; Inuwa, I. Potential Materials for Food Packing from Nanoclay/Natural Fibres Filled Hybrid Composites. Mater. Des. 2013, 46, 391-410. [CrossRef]

24. Dittenber, D.B.; GangaRao, H.V.S. Critical Review of Recent Publications on use of Natural Composites in Infrastructure. Compos. Part A 2012, 43, 1419-1429. [CrossRef]

25. Thomas, S.; Paul, S.A.; Pothan, B.D. Natural Fibers: Structure, Properties and Applications. In Cellulose Fibers: Bio- and Nano-Polymers Composites, 1st ed.; Kalia, S., Kaith, B.S., Kaur, I., Eds.; Springer: Berlin/Heidelberg, Germany, 2011; pp. 3-42.

26. Holbery, J.; Houston, D. Natural-Fiber-Reinforced Polymer Composites in Automotive Application. JOM 2006, 58, 80-86. [CrossRef]

27. Nayak, S.Y.; Sultan, M.T.B.H.; Shenoy, S.T.; Kini, C.R.; Samant, R.; Md Shah, A.U.; Amuthakkannan, P. Potential of Natural Fibers in Composites for Ballistic Applications-A Review. J. Nat. Fibers (online) 2020. [CrossRef]

28. Garcia Filho, F.C.; Oliveira, M.S.; Pereira, A.C.; Nascimento, L.F.C.; Matheus, J.R.G. Ballistic Behavior of Epoxy Matrix Composites Reinforced with Piassava Fiber against High Energy Ammunition. J. Mater. Res. Technol. 2020, 9, 1734-1741. [CrossRef]

29. Monteiro, S.N.; Drelich, J.W.; Lopera, H.A.C.; Nascimento, L.F.C.; Luz, F.S.; Silva, L.C.; Santos, J.L.; Garcia Filho, F.C.; Assis, F.S.; Lima, E.P., Jr.; et al. Natural Fibers Reinforced Polymer Composites Applied in Ballistic Multilayered Armor for Personal Protection-An Overview; Ikhmayies, S., Li, J., Vieira, C.M.F., Margem, J.I., Braga, F.O., Eds.; Springer: Cham, Switzerland, 2019; pp. 33-47.

30. Benzait, Z.; Trabzon, L. A Review of Recent Research on Materials used in Polymer-Matrix Composites for Body Armor Application. J. Compos. Mater. 2018, 52, 3241-3263. [CrossRef]

31. Wang, Z.; Gnanasekar, P.; Nair, S.S.; Farnood, R.; Yi, S.; Yan, N. Biobased Epoxy Synthesized from a Vanillin Derivative and its Reinforcement using Lignin-Containing Cellulose Nanofibrils. ACS Sustain. Chem. Eng. 2020, 8, 30. [CrossRef]

32. Sharma, A.; Thakur, M.; Mandal, T.; Goswami, S. Commercial application of cellulose nano-composites-A review. Biotechnol. Rep. 2019, 21, e00316. [CrossRef]

33. Nissilä, T.; Hietala, M.; Oksman, K. A Method for Preparing Epoxy-Cellulose Nanofiber Composites with an Oriented Structure. Compos. Part A 2019, 125, 105515. [CrossRef]

34. Keplinger, T.; Wang, X.; Burgert, I. Nanofibrillated cellulose composites and wood derived scaffolds for functional material. J. Mater. Chem. A 2019, 7, 2981-2992. [CrossRef]

35. Nair, S.S.; Dartiailh, C.; Levin, D.B.; Yan, N. Highly Toughened and Transparent Biobased Epoxy Composites Reinforced with Cellulose Nanofibrils. Polymers 2019, 11, 612. [CrossRef]

36. Sharma, S.K.; Sharma, P.R.; Lin, S.; Chen, H.; Johnson, K.; Wang, R.; Borges, W.; Zhan, C.; Hsiao, B.S. Reinforcement of Natural Rubber Latex Using Jute Carboxycellulose Nanofibers Extracted Using Nitro-Oxidation Method. Nanomaterials 2020, 10, 706. [CrossRef] [PubMed]

37. Kalia, S.; Kaith, B.S.; Kaurs, I. Cellulose Fibers: Bio and Nano Polymer Composites: Green Chemistry and Technology; Springer Science \& Business Media: New York, NY, USA, 2011. 
38. Demosthenes, L.C.C.; Nascimento, L.F.C.; Monteiro, S.N.; Costa, U.O.; Garcia Filho, F.C.; Luz, F.S.; Oliveira, M.S.; Ramos, F.J.H.T.V.; Pereira, A.C.; Braga, F.O. Thermal and structural characterization of buriti fibers and their relevance in fabric reinforced composites. J. Mater. Res. Technol. 2020, 9, 115-123. [CrossRef]

39. Monteiro, S.N.; Calado, V.; Rodriguez, R.J.; Margem, F.M. Thermogravimetric stability of polymer composites reinforced with less common lignocellulosic fibers-An overview. J. Mater. Res. Technol. 2012, 1, 117-126. [CrossRef]

40. Babu, L.G. Influence of benzoyl chloride treatment on the tribological characteristics of Cyperus pangorei fibers based non-asbestos brake friction composites. Mater. Res. Express 2020, 7, 0153030. [CrossRef]

41. Babu, G.D.; Gudapati, S.P.K.; Prasad, A.V.R.; Babu, K.S. Experimental investigation on mechanical and thermal properties of Esculentus Cyperus fiber reinforced polypropylene composites. Mater. Today Proc. 2019, 23, 557-560. [CrossRef]

42. Rajini, N.; Mayandi, K.; Prabhakar, M.M.; Siengchin, S.; Ayrilmis, N.; Bennet, C.; Ismail, S.O. Tribological Properties of Cyperus pangorei Fiber-Reinforced Polyester Composites (Friction and Wear Behavior of Cyperus pangorei Fiber/Polyester Composites). J. Nat. Fibers 2019, 7, 1-13. [CrossRef]

43. Kalimuthu, M.; Nagarajan, R.; Batcha, A.A.; Siengchin, S.; Anumakonda, V.R.; Ayrilmis, N. Mechanical Property and Morphological Analysis of Polyester Composites Reinforced with Cyperus pangorei Fibers. J. Bionic Eng. 2019, 16, 164-174. [CrossRef]

44. Vijay, R.; Lenin Singaravelu, D. Influence of stacking sequence on mechanical characteristics of Cyperus pangorei fibres based natural fibre composites. Mater. Today Proc. 2018, 5, 8504-8513. [CrossRef]

45. Mayandi, K.; Rajini, N.; Pitchipoo, P.; Jappes, J.T.W.; Rajulu, A.V. Extraction and characterization of new natural lignocellulosic fiber Cyperus pangorei. Int. J. Polym. Anal. Charact. 2016, 21, 175-183. [CrossRef]

46. Govindasamy, P.; Zakaria, M.H.; Bujang, J.S. Fiber characteristics in tropical aquatic plants for handmade papermaking. Bull. Pure Appl. Sci. Bot. 2014, 33, 1-12. [CrossRef]

47. Benazir, J.A.F.; Manimekalai, V.; Ravichandran, P.; Suganthi, R.; Dinesh, D.C. Properties of fibres/culm strands from mat sedge-Cyperus Pangorei Rottb. BioResources 2010, 5, 951-967.

48. Scifoni, S.; Nascimento, F.B. Identification and protection of the agroindustrial landscape of the Japanese immigration in the Ribeira Valley/São Paulo. 2008, pp. 1-26. (In Portuguese). Available online: https: //www.iau.usp.br/sspa/arquivos/pdfs/papers/04505.pdf (accessed on 7 August 2020).

49. Callister, W.D.; Rethwisch, D.G. Materials Science and Engineering: An Introduction, 10th ed.; John Wiley \& Sons: New York, NY, USA, 2018; pp. 665-715. ISBN 9781119405498.

50. American Society for Testing and Materials. D256-0: Standard Test Methods for Determining the Izod Pendulum Impact Resistance of Plastics; American Society for Testing and Materials: West Conshohocken, PA, USA, 2000.

51. American Society for Testing and Materials. D3039-95: Standard Test Methods for Tensile Properties of Polymers Matrix Composite Materials; American Society for Testing and Materials: West Conshohocken, PA, USA, 1995.

52. Morye, S.S.; Hine, P.J.; Duckett, R.A.; Carr, D.J.; Ward, I.M. Modeling of the energy absorption by polymer composites upon ballistic impact. Compos. Sci. Technol. 2000, 60, 2631-2642. [CrossRef]

53. Vieira, S. Analysis of Variance (ANOVA); Ed Atlas: São Paulo, Brazil, 2006.

54. Garcia Filho, F.C.; Demosthenes, L.C.C.; Oliveira, M.S.; Pereira, A.C.; Luz, F.S.; Monteiro, S.N. Piassava Fibers: Morphology and Spectroscopy Aspects; Ikhmayies, S., Li, J., Vieira, C.M.F., Margem, J.I., Braga, F.O., Eds.; Springer: Cham, Switzerland, 2019; pp. 125-131. [CrossRef]

55. Nascimento, L.F.C.; Monteiro, S.N.; Louro, L.H.L.; Luz, F.S.; Santos, J.L.; Braga, F.O.; Marçal, R.L.S.B. Charpy impact test of epoxy composites reinforced with untreated and mercerized mallow fibers. J. Mater. Res. Technol. 2018, 7, 520-527. [CrossRef]

56. Braga, F.O.; Simonassi, N.T.; Cabral, A.C.; Monteiro, S.N.; Assis, F.S. Tensile and Impact Properties of Two Fiber Configurations for Curaua Reinforced Composites; Meyers, M.A., Benavides, H.A.C., Brül, S.P., Colorado, H.A., Dalgaard, E., Elias, C.N., Figueiredo, R.B., Garcia-Rincon, O., Kawasaki, M., Langdon, T.G., Eds.; Springer: Cham, Switzerland, 2017.

57. Maciel, N.O.R.; Ferreira, J.B.; Vieira, J.S.; Ribeiro, C.G.D.; Lopes, F.P.D.; Margem, F.M.; Monteiro, S.N.; Vieira, C.M.F.; Silva, L.C. Comparative tensile strength analysis between epoxy composites reinforced with curaua fiber and glass fiber. J. Mater. Res. Technol. 2018, 4, 561-565. [CrossRef]

58. Martini, A.L.B.S.; Gouvêa, R.A.; Oliveira, M.P.; Cândido, V.S.; Monteiro, S.N. Characterization of epoxy composites incorporated with sugarcane bagasse fibers. Mater. Sci. Forum 2014, 775, 102-106. [CrossRef] 
59. Luz, F.S.; Garcia Filho, F.C.; Gómez del-Río, M.T.; Nascimento, L.F.C.; Pinheiro, W.A.; Monteiro, S.N. Graphene-incorporated natural fiber polymer composites: A first overview. Polymers 2020, 12, 1601. [CrossRef]

60. American Society for Testing and Materials. D638-17: Standard Test Method for Tensile Properties of Plastics; American Society for Testing and Materials: West Conshohocken, PA, USA, 2014.

61. Mohanty, S.; Verma, S.K.; Nayak, S.K. Dynamic Mechanical and Thermal Properties of MAPE Treated Jute/HDPE Composites. Compos. Sci. Technol. 2006, 66, 538-547. [CrossRef]

62. Canevarolo, S.V., Jr. Techniques for Polymer Characterization; Ed Artliber: São Paulo, Brazil, 2003. (In Portuguese)

63. Lucas, E.F.; Soares, B.G.; Monteiro, E. Polymer Characterization; Ed E-papers: Rio de Janeiro, Brazil, 2001. (In Portuguese)

C 2020 by the authors. Licensee MDPI, Basel, Switzerland. This article is an open access article distributed under the terms and conditions of the Creative Commons Attribution (CC BY) license (http://creativecommons.org/licenses/by/4.0/). 